\title{
Reformulando el sujeto, los géneros literarios y el compromiso con la historia: la escritura del yo en la obra de Marta Sanz
}

Vara Ferrero, Natalia

Universidad del País Vasco, España

natalia.vara@ehu.eus

Cita sugerida: Vara Ferrero, N.(2018). Reformulando el sujeto, los géneros literarios y el compromiso con la historia: la escritura del yo en la obra de Marta Sanz. En C. Somolinos Molina (ed.), "Escrituras del cuerpo: Marta Sanz". Olivar, 18 (27), e023. https://doi.org/10.24215/18524478e023 


\title{
Reformulando el sujeto, los géneros literarios y el compromiso con la historia: la escritura del yo en la obra de Marta Sanz
}

\author{
Rethinking the subject, the literary genres and the commitment to history: the writing of the self in Marta Sanz \\ work \\ Natalia Vara Ferrero \\ Universidad del País Vasco, España \\ natalia.vara@ehu.eus
}

\section{RESUMEN:}

Las cuestiones relacionadas con la autobiografía se han convertido en elementos centrales del debate literario actual. En ese contexto se sitúa la escritura de Marta Sanz, una escritora que renueva y subvierte los modelos más ortodoxos de la escritura del yo. Este trabajo, centrado en su poesía y en su novela autobiográfica, estudia cuál es la concepción del sujeto en su obra, cómo reformula los géneros autobiográficos y cuál es la relación que sujeto y texto establecen con su contexto histórico y con los lectores. En definitiva, esta investigación trata de dar respuesta a una cuestión central: ¿qué sentido tiene para Marta Sanz narrarse a sí misma y contar su existencia, en un contexto como el actual, en el que los límites entre realidad y ficción son tan inestables y difusos?

Palabras Clave: Marta Sanz, Escritura del yo, Poesía, Novela, Ensayo.

\section{Abstract:}

Issues related to autobiography have become central elements of the current literary debate. This is the context of the writing of Marta Sanz, a writer who renews and subverts the most orthodox models of self-writing. This essay, centered in her poetry and autobiographical novel, deals with her idea of the subject, how she reformulates autobiographical genres and which is the relationship that subject and text establish with their historical context and with their readers. In fact, this research tries to answer a nuclear question: What does it mean for Marta Sanz to narrate herself and tell her existence in a context such as the present one, a context in which the boundaries between reality and fiction are so unstable and diffuse?

KEYWORDS: Marta Sanz, Self-writing, Poetry, Novel, Essay.

La escritura autobiográfica, entendida como peculiaridad significativa de nuestra época, parece que se ha convertido desde hace algunos años en el campo de batalla en el que se dirimen algunos de los temas centrales del debate literario contemporáneo (Loureiro, 1991, p. 3). Se trata de un tipo de literatura que parece enmarcarse en un amplio "hipergénero autobiográfico" (Scarano, 2014, p. 55) que ha puesto de manifiesto que en la actualidad el yo y sus vivencias íntimas ocupan una posición privilegiada dentro y fuera de la ficción. Asimismo, esta cuestión ha centrado las investigaciones sobre cómo se articulan las relaciones entre ese yo y el mundo, haciendo saltar a la arena teórica conceptos tan cargados de significados como sujeto, historia, lenguaje, discurso, referencialidad, representación, esencia o poder. No es menos importante que este sujeto creador que busca nuevas maneras de manifestar su subjetividad, por medio de estrategias que lo alejan de las posiciones más tradicionales y ortodoxas, haya invadido con un mestizaje de géneros y dimensiones diversas manifestaciones artísticas y goce de manifiesta popularidad (Scarano, 2014, p. 55).

La ambigüedad y la indeterminación referencial que este tipo de autobiografías fronterizas con la ficción exhiben (Alberca, 2007, p. 155) ante el lector actual, incluso cuando dicha confusión no existe y es únicamente un juego, han propiciado que ese lector haya visto cambiar su posición ante el texto, pues incapaz de diferenciar entre ficción y realidad, su proceso de descodificación y de organización de la información que proviene del discurso autobiográfico lo ha obligado a posicionarse, a ser consciente de que no existen ni un único código ni una única perspectiva. Además, se ha visto obligado a admitir que las fronteras entre 
esas posiciones son difíciles de mantener, con lo que sus lecturas se pueden deslizar una y otra vez entre un pacto autobiográfico, uno autoficcional y otro ficcional. En este contexto de controversia teórico-práctica es donde se sitúan no sólo las ideas sobre la "escritura del yo" de Marta Sanz (explicitadas en el interesante ensayo No tan incendiario), sino también su práctica escritural más autobiográfica (la que atañe a la novela autobiográfica La lección de anatomía y a sus poemarios).

La formulación de ese "hipergénero autobiográfico" en manos de Sanz resulta de interés por diversas razones. La principal es que la escritora no sólo parece haber reflexionado ampliamente sobre esta modalidad escritural, sino que también se sirve de ese conocimiento para llevar a cabo un ejercicio de subversión profundo e indisimulado de los modelos más ortodoxos. Y lo hace desde una posición que podríamos denominar triple: su condición de creadora, su género y su posición como miembro de la sociedad actual. Así, la escritora reformula y vuelve a dotar de significado un tipo de texto fuertemente codificado por la tradición y caracterizado por Sidonie Smith como un relato mayoritariamente masculino e individualista:

Al privilegiar al yo autónomo o metafísico como agente de sus propios logros, y al situarlo con frecuencia en posición de antagonista respecto al mundo, la "autobiografía” promueve una concepción del ser humano que valora la unidad individual y la separación, a la vez que devalúa la interdependencia personal y comunitaria (Smith, 1991, p. 93).

Elizabeth Bruss defiende que la elección de un género literario por parte de un autor explicita las intenciones de ese creador y la determinación de las posibilidades de recepción de ese texto (1991: 64); el resultado de esta decisión creativa vinculada con el contexto cultural e histórico es algo que Marta Sanz no ignora. Tampoco ignora que los géneros, subgéneros y modalidades creativas no son inmutables, que ese "hipergénero autobiográfico" es una forma literaria tan sometida a los cambios asociados al tiempo histórico en el que se escribe y se lee como todos los demás, y que la capacidad de cuestionar y reformular aquellos moldes que hereda y de los que se sirve para crear sus obras es una parte de sus privilegios como escritora:

Porque sé que la literatura sirve, me gustan esos autores que se obligan a darle un revolcón a los géneros en cada texto que escriben: el éxito de un género viene condicionado por su capacidad para conectar con una gran masa acrítica [...] Me gustan los autores que dan un paso más allá de lo familiar -el zapato no roza el empeine- y cuestionan los esquemas retóricos desencajando la propia realidad. Estos autores no tienen que ser necesariamente oscuros: tan sólo, mostrar cierto arrojo. Los géneros están ahí para ser subvertidos - más que utilizados- en la convicción de que el mundo no está bien hecho y de que rebelarse contra los géneros que lo codifican y lo legitiman no es quizá una actividad autónoma, independiente, de lo que sucede en la calle, en las empresas o en las comunidades de vecinos (Sanz, 2014a, p. 90-91).

Punto por punto, la novela y los poemas de marcado poso autobiográfico de la escritora desmontan y ponen en cuestión los puntales sobre los que se ha asentado un discurso autentificador "que pretende ser leído como la verdadera imagen que de sí mismo testimonia el sujeto” (Pozuelo, 2006, p. 24), un autor que se compromete con su lector a decir la verdad y nada más que la verdad (Lejeune, 1991, p. 57) en sus formulaciones más ortodoxas. ¿Cuál es por tanto esa formulación que ofrece Marta Sanz desde su obra ensayística, sus narraciones y sus composiciones poéticas? ¿Qué ofrecen estos textos que parecen decirnos con inusitada desfachatez "esa soy y no soy yo"? ¿Cuáles son las estrategias de las que se vale la escritora y cuáles sus objetivos?

Tomando como punto de partida estas cuestiones, tres van a ser los aspectos que vamos a revisar partiendo de las reflexiones que la autora formula en No tan incendiario y que lleva a la práctica en algunos de sus textos literarios: trataremos de desvelar cuál es la concepción del sujeto que maneja, cómo formula esos géneros autobiográficos sobre los que trabaja y cuál es la relación que se establece entre ese sujeto, el texto y su contexto. Asimismo, trataremos de indagar cuál es el sentido que tiene para Marta Sanz ese narrarse a sí misma, ese relatar su existencia para otros, en un contexto como el actual, en el que los límites entre la verdad y la ficción resultan tan esquivos.

El autor, nos dice Marta Sanz, "es un concepto que se relaciona con el yo, pero que no es exactamente yo" (Sanz, 2014a, p. 95). El sujeto de La lección de anatomía y de los poemarios de la autora emana de esa 
misma concepción: el yo que nos habla desde la dimensión literaria no es un personaje netamente ficcional, ajeno a la realidad externa, pero tampoco es exactamente quien hace la compra o quien publica libros, concede entrevistas o denuncia su incapacidad para resolver esa supuesta paradoja ante cuestiones mayor importancia ("No me siento preparada para responder a tantas preguntas IMPORTANTES y, a mi vez, me interrogo: ¿sirven para algo estas preguntas que no tienen que ver con el precio de los alimentos?” [Sanz, 2014a, p. 99]).

Ese sujeto no se concibe como una esencia verdadera, existente a priori, un individuo de perfiles definidos, alguien que se conoce perfectamente a sí mismo y que es capaz de trazar su devenir sin perder de vista la unidad de vida que lo ha caracterizado (Gusdorf, 1991, p. 13). Desde luego, tampoco podemos hablar de un sujeto que siente la necesidad de relatar sus vivencias porque cree que se trata de una existencia ejemplar digna de interés (Gusdorf, 1991, p. 13), tras la cual subyace un deseo de permanencia no confesado. Ni tampoco nos hallamos ante un ser evasivo, ante una construcción discursiva que entiende a ese yo como una máscara tras la que está la nada, en consonancia con la lectura figurativa y des-figurativa propuesta por De Man (1991, p. 16). El yo que emana de las concepciones teóricas y los textos literarios de la escritora presenta una doble agencialidad que es propia del yo lírico, un sujeto que entreteje los datos biográficos con la literatura, "sin clausurar su operatividad ficcional ni referencial" (Scarano, 2014, p. 34 y 62), en busca de un relato de vida construido a través de modelos y moldes líricos y narrativos. En las huellas de ese yo siempre queda algo de su verdad, detrás de los tropos y las figuras siempre quedan rastros de sus experiencias y sus vivencias, pese a que la autora no se lleve a engaños y confiese que "es tan difícil aprehender el yo como no aprehenderlo" (Sanz, 2014a, p. 105). Sin duda, la memoria de la que surge esa escritura autobiográfica sirve para volver a reflexionar e interpretar esa experiencia anterior, asignando significados y buscando sentidos globales "por medio del énfasis, la yuxtaposición, el comentario y la omisión" (Smith, 1991, p. 96). Al contar una historia, nos dice Sanz, no se cuenta inocentemente, sino con una condición intencional inseparable de la naturaleza ideológica de la que se dotará al texto. En otras palabras, la autora se proyecta en esos yoes ficcionales sin diluirse, sin perder la posición de autoría, recuperada frente a una literatura concebida estructuralmente, únicamente como texto, y empeñada en desconectar al autor y a sus intenciones del lector todopoderoso.

Una de las particularidades de la escritura autobiográfica de Marta Sanz proviene de la conciencia de que la elaboración de la identidad individual no es posible sin los otros. En sus poemarios, y de modo relevante en La lección de anatomía, la formulación de la identidad no aparece como un proceso unipersonal; al contrario, se traza como un proceso relacional en el que otros agentes participan necesariamente. Esta concepción del yo implica no sólo alejar la escritura autobiográfica de una dimensión esencialista, sino que también permite poner en primer plano las claves éticas de un sujeto que somete a revisión su memoria para estudiar sus relaciones con aquellos frente a los que y junto a los que se ha constituido (la familia, los amigos, los amores, los otros autores, las lecturas y la práctica escritural), situándose en unas coordenadas socio históricas que si no lo determinan, al menos han servido para condicionarlo ("No hace falta tatuarse/ el cuerpo/ para que esté/ lleno de Historia” [Sanz, 2015, p. 45]). Esta concepción del yo con los otros se asienta en la sugestiva noción de "auto-escritura" ética del sujeto que lanza Ángel Loureiro basándose en la propuesta filosófica de Emmanuel Levinas (2000, p. 19). Desde esta perspectiva, en la escritura autobiográfica la autonomía se cambia por la colectividad, el yo se construye como respuesta a las vivencias que ha compartido con los otros, adquiriendo así una dimensión relacional que nos permite entender mejor los episodios y las figuras que jalonan el devenir de la Marta niña hasta la adulta en La lección de anatomía. Dividiendo en tres las etapas (infancia, adolescencia, juventud) de un aprendizaje en el que la cuestión de género adquiere una enorme relevancia, ese sujeto femenino se construye a partir y en contra de las figuras de su género: la madre, las tías, la abuela, las compañeras de colegio e instituto, las de la universidad y las que encuentra en diferentes puestos de trabajo. De la madre (figura centralísima) aprende el poder del relato realista, la honestidad inflexible, y contra ella erige la legitimidad de la mentira y la capacidad para ensayar distintas máscaras; en sus tías vislumbra por primera vez las relaciones de dependencia que pueden establecerse con el otro género; gracias a las niñas del colegio desarrolla estrategias de supervivencia y entiende la importancia de las relaciones de poder; los 
valores de la amistad aparecen en la adolescencia y la juventud, pero también la necesidad de ensayar diversas máscaras y la conciencia de que en un yo habitan distintos sujetos ("He sido rebelde y estudiosa. Hembra y varón. Dulce y agresiva. Empollona y gimnasta. Juguetona y adusta” [Sanz, 2014b, p. 187]). El proceso de maduración del yo pasa por la prueba de distintos disfraces identitarios, disfraces que le permiten adaptarse a los contextos en los que se mueve y sobrevivir, ajustándose y alejándose de los diversos estereotipos y cánones.

En este sentido, resulta muy significativo el capítulo "Lágrimas", pues una anécdota aparentemente intrascendente encierra en sí el sentido de esa búsqueda de identidad que aborda el yo. A un lado de la puerta del baño, frente al espejo y fascinada por la belleza de su rostro lloroso, tenemos a la Marta niña empeñada en la desesperanza, regodeándose en unas lágrimas sin causa aparente ("No lloro por nada. Lloro porque me empeño en ser alguien depresivo y me enmaraño en la paradoja de que, al buscar la tristeza propia o la conmiseración de los otros, experimento goce físico. [...] Lloro porque hoy me toca llorar" [Sanz, 2014b, p. 112]); al otro, la desconcertada madre, espectadora indispensable para este espectáculo, espejo necesario para este juego de disfraces que la adolescente lleva a cabo ("Mi madre no sabe si llorar conmigo o ponerse a reír" [Sanz, 2014b, p. 112]). Un episodio aparentemente anecdótico encierra en sí las claves de la conformación de la identidad del yo, necesitado de ese otro para definirse como individuo y como mujer, en un proceso formativo en el que se prueban y desechan modelos a lo largo del camino. Y que no cesa de cuestionarse y de juzgarse ni siquiera cuando aparta la mirada del pasado y la centra en el presente de su día a día, en sus actitudes y reacciones frente a la injusticia de la situación de los otros, tal y como ocurre en el siguiente poema:

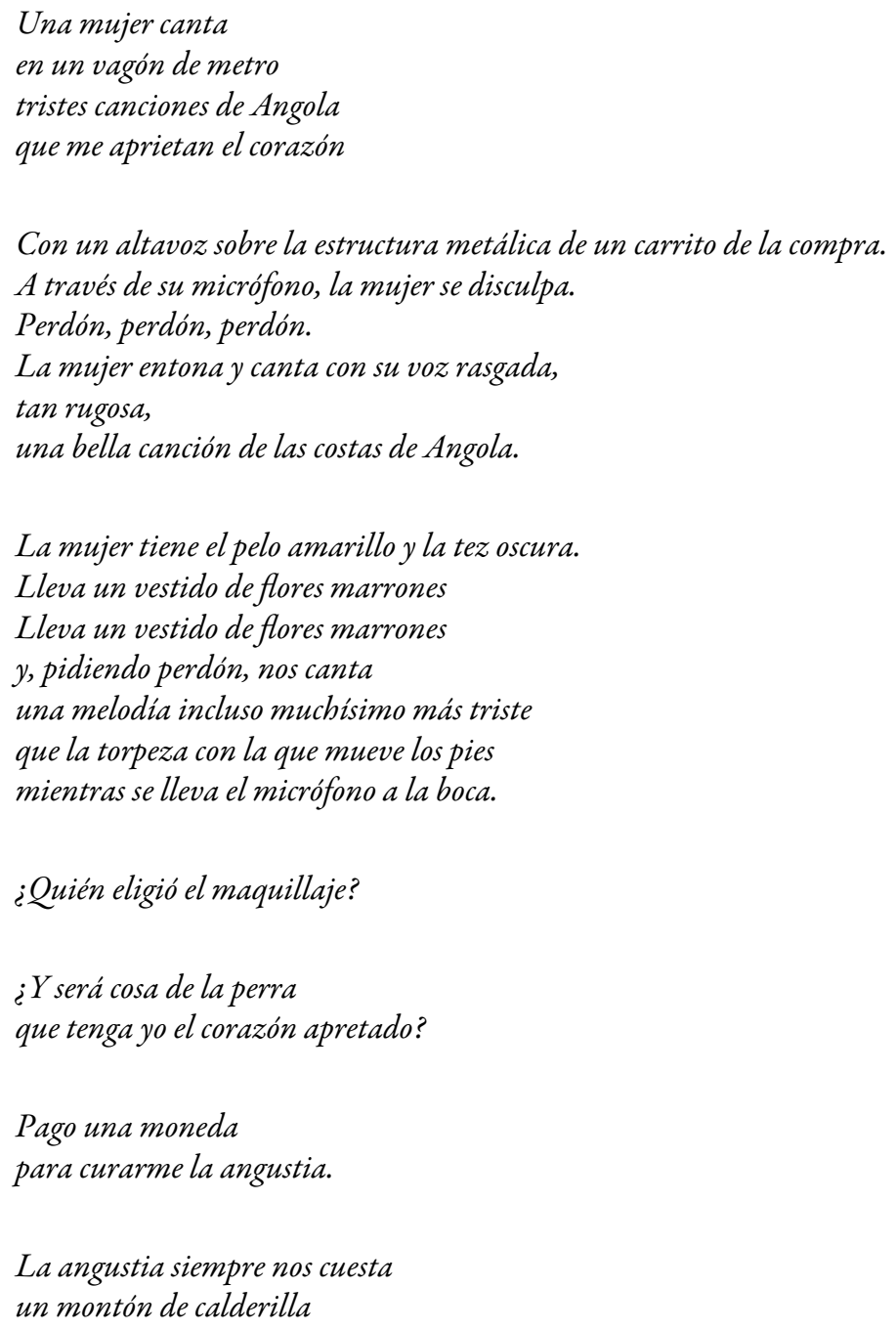


Fuente: (Sanz, 2010, p. 40-41).

Tanto en La lección de anatomía como en los poemarios de la autora nos encontramos con un yo que bucea en la vida presente y en la memoria para poder engarzar y dotar de sentido el relato de su existencia. Se trata de un yo inclemente, mordaz, que asume la honestidad de señalarse inmisericorde, pero que al mismo tiempo se sirve de estrategias literarias y de juegos inter y metatextuales para recordarnos continuamente que no debemos olvidar la dimensión ficticia a la que también pertenece, una dimensión que lo conecta nuevamente con la realidad. La identidad ficcional, fácilmente reconocible, surge de un ejercicio de reflexión y enjuiciamiento en el que el yo actual mira con ironía, escasa ternura y un alto grado de consciencia al sujeto que fue o que es. Un yo femenino que para dibujarse, para definirse, tiene que entablar diálogos intertextuales e interdiscursivos con otros modelos ("Cómo calzarse/ la palabra mujer/ sin que el pie zancajee/ dentro del zapatito" [Sanz, 2013: 32]), con otros contextos y con otras posibilidades de ser escritora. Y lo hace mediante una actitud combativa, que implica cuestionar los mitos y los tópicos en los que la mujer actual, supuestamente autónoma y liberada, aún está atrapada, al igual que lo estuvieron otras antes que ella:

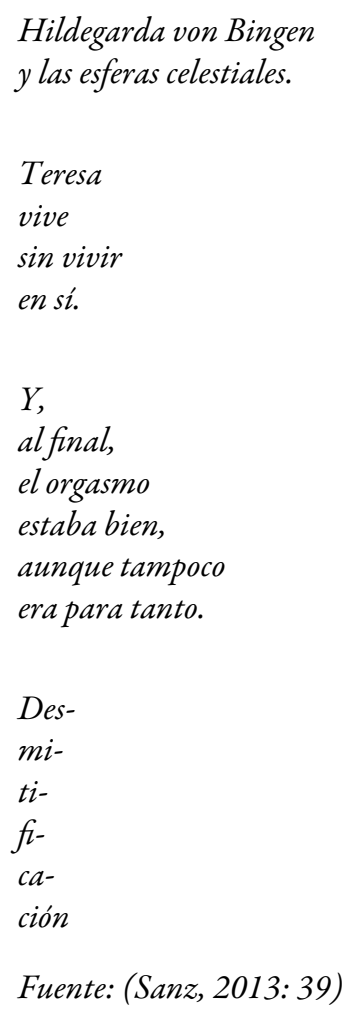

Sidonie Smith, en su estudio sobre la poética de las autobiografías femeninas, señala la neutralidad imposible de este tipo de escritura:

la forma que toman las estrategias narrativas y dramáticas de la autobiógrafa, revela más sobre el momento presente de su autoexperiencia que sobre su pasado [...] revela el modo en que la autobiógrafa se sitúa a sí misma y a su historia en relación con las ideologías culturales y los modelos de identidad (1991, p. 97).

Sin embargo, se olvida la teórica de que tampoco las formas genéricas son inocentes, puesto que estos modelos también conllevan significado en relación con los contextos socio-políticos en los que son utilizados. Los géneros literarios tienen formas estables que los hacen reconocibles e identificables por los lectores, unas formas que sirven para distinguirlos de otros géneros y que aparecen asociadas a ciertas funciones en virtud del momento en que se leen. Pero las características textuales no son invariables, los géneros son codificaciones que tienen una condición líquida, que los hace permeables y maleables en manos de los escritores. Las 
innovaciones y transformaciones en la concepción de los géneros son claves en la historia literaria, pues no hay evolución sin cambio y menos si una autora tan consciente como Marta Sanz decide implicarse en ellos. "Los géneros están ahí para ser subvertidos", reivindica, consciente de que esas formas codificadas responden a distintas concepciones de la realidad y de la relación entre ficción y mundo (Sanz, 2014a, p. 91). Y esa subversión implica que es posible intervenir en los aspectos formales de los hipergéneros autobiográficos para que cumplan nuevas funciones en la sociedad, para que planteen nuevas perspectivas ideológicas y para que ofrezcan a los lectores nuevos modos de concebir el mundo. No sólo la autobiografía es colonizada por estrategias cuestionadoras, sino que poemarios como Perra mentirosa/Hardocre, Vintage o Cíngulo y estrella ponen en entredicho el lenguaje, los discursos o los subgéneros líricos con los que entroncan, llevando a cabo una metamorfosis formal que genera nuevas posibilidades textuales, pero también nuevos significados que respondan a las coordenadas de un momento histórico o un género literario determinado. En todos los casos, ya sea en la escritura novelesca, ya sea en la poética, dos son los aspectos sobre los que se apuntala la obra de Sanz: la verosimilitud literaria y la voluntad de no diluir la presencia de un autor que se sabe responsable de esos textos. Volvamos la mirada a sus palabras en No tan incendiario:

lo que importa de un libro autobiográfico no es su fidelidad al orden y textura de los acontecimientos narrados, la capacidad de mímesis con los momentos de una vida real, sino su verosimilitud como texto. Sin embargo, a veces -quizá siempre- la franqueza es el tiro que se escapa por la culata cuando emprendemos el proyecto de construir el yo enmascarado (...) Del autor es la patita que siempre se enseña por debajo de la puerta. De él y del discurso que amplifica o contra el que se construye. Vuelve a ser clave el concepto de responsabilidad (Sanz, 2014a, p. 107).

Como escritora comprometida con una visión de la realidad, en la que no renuncia a tratar de intervenir mediante su obra y el papel que desarrolla en el marco del sistema literario, Sanz es consciente de que la forma y el estilo de los textos no puede desconectarse del aspecto ético y político de la escritura. Los de la autora son textos que cuestionan y tensan las formas, sin romperlas, subrayándolas y generando nuevas posibilidades en ellas. Dando la espalda a la idea de una escritura neutra, utiliza todos los recursos expresivos, las estrategias literarias y las modificaciones estructurales a su alcance: un lenguaje incisivo, incómodo y desasosegante; la revisión y reformulación de tipos y modelos femeninos: discursos literarios o sociales profundamente reformulados; reflexiones metaliterarias y autorreferenciales; $y$, por último, un serio cuestionamiento de la estructura y la organización de géneros ya codificados. Partiendo de un nuevo realismo, que la autora define como una perspectiva que surge de la toma de conciencia de que "tú eres un escritor y tienes la confianza de que tus libros parten de la observación de la realidad y de alguna manera van a repercutir en ella" (en Niebla, 2015), apuesta por investigar y probar distintos estilos para lograrlo, sin caer en modelos ya caducos, como el realismo decimonónico o los tópicos del romanticismo anterior. Así, la autobiografía novelesca se renueva gracias a una propuesta que se formula como una novela que no busca la empatía ni la identificación fácil del lector nostálgico, sino que se articula como una progresión episódica que omite y resalta episodios a voluntad, que se vale de una mirada implacable que refleja el ejercicio de autopsia que el yo se hace a sí mismo para mostrar al lector los mecanismos por los cuales lo íntimo deriva de los intereses genéricos, sociales y económicos que lo han rodeado (Chirbes, 2014, p. 12). Así, La lección de anatomía, su novela autobiográfica, construye una vida y da forma a un cuerpo ${ }^{1}$, pero lo hace de un modo verosímil, formulando una metáfora que cobra sentido en una realidad que impone a la mujer no sólo distintas máscaras, sino también diversos discursos y moldes para narrarse. Contra esos modelos del mundo actual dispara Sanz en un discurso que se permea de la ficción y de referentes que de ella vienen, un discurso hondamente reflexivo, en el que el yo actual se examina e interpreta. Esta autonarración articula una construcción de la identidad progresiva, equilibrada entre la omisión y la alusión, que engarza diversas perspectivas y distintas máscaras por parte del sujeto, une fragmentos reflexivos con episodios rápidamente resueltos, secundada por distintos personajes que configuran un universo mayoritariamente femenino. Esa estructura se abre con un fragmento que determinará la interpretación del proceso de aprendizaje que emprende la niña Marta, aunque las claves de lectura que ofrece sirven para anclar La lección de anatomía al aquí y al ahora, obligando al lector a 
preguntarse precisamente por qué la clave de la felicidad de la autora es el desaprendizaje de lo interiorizado en ese proceso ("Lo he olvidado todo menos mi propio orgullo herido y la desilusión de mi madre por mi torpeza y lentitud" [Sanz, 2014b, p. 21]). La aceptación de un yo que llega al presente despegándose de lo que la sociedad exigía, de las estrategias de autoprotección y de la exigencia hacia uno mismo, es el punto de partida de una narración que consiste en contar precisamente cómo se ha llegado hasta aquí, cómo el despojarse de lo que le han exigido (y se ha exigido) le ha permitido alcanzar la felicidad.

Veamos qué ocurre en la escritura poética de la autora. Una revisión de los rasgos tradicionales de la poesía amorosa caracteriza uno de sus poemarios autobiográficos, Cíngulo y estrella. La celebración del amor de una pareja con una larga convivencia se lleva a cabo sin recurrir a los tópicos clásicos del género y por medio de un nuevo lenguaje, una estrategia renovadora que parece intuirse cuando en los versos iniciales del volumen, el yo poético señala al canon con el que entronca y contra el que se levanta: "Petrarca resucita/ en la fontanela/ del cráneo. // Me grita cosas/ y viste/ como un fatuo/ cardenal” (Sanz, 2015, p. 7). El blanco del ataque no es exclusivamente la desgastada lista de tópicos amorosos que hemos heredado y que determina nuestra concepción del amor, sino también la visión capitalista y consumista que ha penetrado en nuestra concepción de las relaciones, convertidas en objeto de disfrute rápido y exhibición impúdica. En Cíngulo y estrella se exalta un amor que podríamos denominar vulgar, ni encontramos al otro idealizado ni asistimos a muertes trágicas que lo hacen pervivir más allá de la muerte; lo que proponen estas composiciones es la celebración de una relación monógama larga y estable, en la que hay memoria de la vida individual y común de la pareja, celos confesos ("Debería tener mucho cuidado/ esa chica guapa a quien no conocí" [Sanz, 2015, p. 14]), una defensa de las parcelas de intimidad individual imprescindibles para que se mantenga el amor ("Tú no quieres saber/ qué escondo yo/bajo el abrigo" [Sanz, 2015, p. 39]) y de la confianza cotidiana necesaria para la convivencia ("Ahora,/ya me acuesto/ con mi pijama rosa.// Y tú,/ con tu pijama azul.// De la seguridad social" [Sanz, 2015, p. 37]). Una reivindicación de un amor que sobrevive a la monotonía del día a día ("No se puede hablar/ del amor/ en abstracto" [Sanz, 2015, p. 44]), que no se ha regodeado en los momentos trágicos con tufillo de falsedad ("No tenemos paisajes/ ni cumbres borrascosas" [Sanz, 2015, p. 52]), basado en el respeto al otro y a su individualidad ("Cuánto te agradezco/ que no me hayas puesto tus palabras/ encima de la boca” [Sanz, 2015, p. 56]); en definitiva, una relación asentada sobre lo que realmente importa, el valor con el que se abre el volumen ("Mientras escribo de ti/ recupero el amor" [Sanz, 2015, p. 8]) y que desliza los últimos versos del poemario: "Sigo contigo./ Porque te quiero mucho./ Cualquier otro argumento/ sería maquinación” (Sanz, 2015, p. 59).

El último aspecto que destaca en la propuesta autobiográfica de Marta Sanz tiene que ver con la relación de esa escritura con el contexto del que surge y hacia el que se dirige. Como señala acertadamente la propia escritora en No tan incendiario, los textos literarios, como los objetos culturales en general, "dialogan entre sí, pero fundamentalmente dialogan con lo real: parten de la realidad y a la realidad vuelven” (Sanz, 2014a, p. 33). La literatura no se crea en una torre de marfil, surge desde una perspectiva individual y en un contexto sociohistórico determinado al que vuelve, al pasar a las manos y a los ojos de los lectores. Que lo íntimo es colectivo en la escritura autobiográfica de Marta Sanz no puede ponerse en duda, las vivencias de ese yo no se articulan narrativamente para autodescubrirse narcisísticamente, pues no aspira a exhibir una exitosa etiqueta en un mercado literario en el que el autor se ha transformado en objeto de consumo; las narraciones y poemas en las que se vuelcan las vivencias del yo permiten pensar y trazar una verdad del vivir cotidiano. Autoconstruirse forma parte de un proceso social en el que el sujeto se retrata para servir a los demás, para quitarles la venda de los ojos haciéndolos conscientes de las contradicciones y las falsedades que los envuelven en su día a día (“QQué poderoso placer se experimenta/ al desprender,/ arrastrando con la uña,/ la viruta caoba/ de una capa/ de barniz?” [Sanz, 2010, p. 41]). La escritura autobiográfica es un ejercicio de compromiso con la sociedad que implica, en el caso de la autora:

An ethicopolitical gesture that entails a double responsibility: in the first place, by signing, the self is responding for itself before the other; and in the second not only the signature responds to the other's injunction to speak, but that same logic of 
alterity implies that the signed texts is also a legacy to an other that not simply receives it but has to cosign it and thus take responsibility for it. Autobiography comes from the other and is for the other (Loureiro, 2000, p. 24).

Este hipergénero se reformula como un ejercicio autoexegético de compromiso para con los receptores, una reflexión y rememoración que se funda en el sentido ético que emana de las experiencias pasadas y de las relaciones con los otros, que son los elementos que han confirmado al sujeto actual. Los modelos, las relaciones, el lenguaje y los discursos heredados conforman al sujeto, pero este no renuncia a examinarse y decirse desde su consciencia, insiste en fijar su memoria, sus encuentros y desencuentros, sus relaciones con los otros en un gesto de autocreación lingüístico. Este gesto de autoconocimiento y afirmación no sólo traza la identidad del yo que ofrece la autora en los textos, sino que partiendo de la dimensión ética que origina la autoconfiguración se ve impulsado hacia los otros, los lectores, afirmando una dimensión vocativa que Sanz reconoce:

Si el autor - palabra, por lo demás, ya muy desprestigiada- aspira a mirar desde otro sitio, a producir inquietud, a colocar a sus lectores en un brete cognoscitivo y/o ideológico, a propiciar una acción, a renombrar lo real para compartir con nosotros su comprensión - parcial, pero única- de la misma, a intervenir en la sociedad o a transformarla; si un autor aspira a todo eso, necesita de un lector exigente, esforzado, participativo: un lector con el que entablar una conversación (Sanz, 2014a, p. 136).

En este sentido, la referencialidad y sus luchas con las injerencias de la ficción quedan desplazadas en el discurso del sujeto, pues los elementos que componen la memoria de esa "conciencia en busca de su verdad personal" (Gusdorf, 1991, p. 16) son considerados a la luz de su sentido como relato ofrecido al otro (Loureiro, 2000, p. 16), y quedan desvirtuados como sucesos o encuentros que deberíamos contrastar en la biografía de esa escritora para ver si nos dice o no la verdad. Es más, el funcionamiento ético y social de los textos de Marta Sanz adquiere pleno sentido pues, en esa revisión de las memorias, muchos de los momentos que se evocan tienen que ver con sus vivencias desde su género femenino y desde su sociedad, desde la conciencia de los modelos de mujer tradicionales que han pujado en su educación y desde la inquietud de una realidad en la que "depender de una nómina o quedarse en paro" (Sanz, 2014, p. 34) es algo que tarde o temprano nos ocurrirá a todos. De ahí que la autora, sin escatimar la ironía y la alusión juanramoniana, señale en uno de sus poemas su rechazo hacia un tipo de poesía "pura”, y que apueste por palabras que estén "manchadas" por la realidad y que necesiten de una descodificación colectiva:

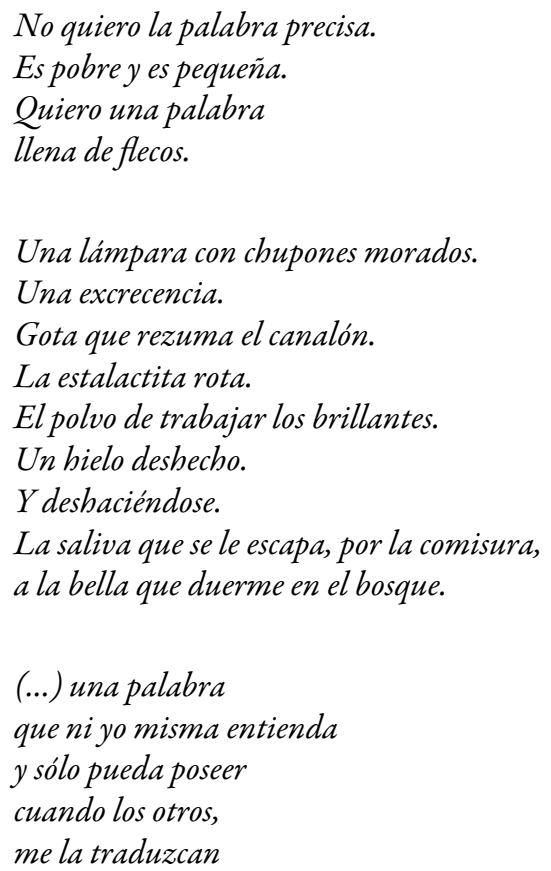


Fuente: (Sanz, 2010, p. 19).

Esta perspectiva, la propia de un discurso del yo para sí mismo y para el otro, saca a la escritura autobiográfica del callejón sin salida al que lo habían abocado los debates entre realidad y ficción, y lo resitúa en un espacio en el que el sujeto se singulariza por medio de su aceptación o rechazo de "lo otro", los valores sociopolíticos, colectivos o simbólicos que conoce en su trayectoria vital, y no pierde de vista su dimensión vocativa y performativa en la realidad extratextual. Como nos demuestran la novela autobiográfica y los poemarios autoficticios de la autora, el acto de creación de ese sujeto no se puede comprender como un ejercicio meramente referencial ni como un juego ficticio, sino que implica un impulso y deseo de alcanzar cierta verdad por medio de la dimensión ética del yo, un impulso que nunca será culminado y que únicamente llegará a los otros como incompleto, pero en un gesto de compromiso que une al autor con su sociedad, a la que ofrece un relato individual en un gesto de solidaridad y compromiso que no es inocente ni inocuo:

\author{
La tensión de la página,

Estos textos, al igual que el resto de la producción literaria de la autora, "pasan por pensar en el ahora y en el aquí, por ver la viga en el ojo propio, por reconocer el peso y el volumen de nuestras alienaciones cotidianas" (Sanz, 2014a, p. 42), y en consecuencia buscan verdades individuales y compartidas que permitan al autor asumir sin complejos su visión ideológica, algo que sólo es posible si se deja de concebir al lector como despótico cliente para comenzar a pensarlo como un cómplice y agente del cambio. Una literatura poco complaciente, que parte de una visión clara de lo determinados que están los discursos y las imágenes entre las que nos movemos y gracias a los que concebimos el mundo, que trata de volver a su comunidad ofreciéndole otra perspectiva. Una literatura, en definitiva, asentada en un diálogo que tenga como tema principal la situación del mundo:

Porque el mundo no está hecho solo de textos y de verdad nos faltan realidades, es necesario contar historias y volver, en definitiva, a la literatura como forma de conciencia de la vida y como capacidad de nombrar e intervenir en el mundo (Sanz, 2014a, p. 148)

Los textos autobiográficos de Marta Sanz liberan al yo de los modelos escriturales de la autobiografía tradicional, desmitificando la singularidad del sujeto esencialista y coherente, y desafían a los receptores que se aproximan a la literatura para pasar un buen rato o para encontrar vidas ejemplares que poco tienen que ver con la suya. Proponen a cambio un nuevo tipo de literatura, metonímica, en la que lo individual es metáfora de lo colectivo, tanto en su configuración como en el alcance de su relato, pues su ADN no singulariza al individuo frente a los demás, sino que lo entronca en la memoria de un "ADN histórico, cultural y familiar" (Sanz, 2013, cubierta). Esta literatura autobiográfica se formula como una fuente de conciencia sobre el mundo que permite que el autor, con la complicidad del lector, convierta la escritura de nuevo en un arma cargada de futuro: 


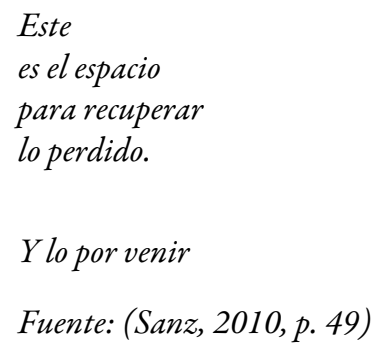

\section{REFERENCIAS}

Alberca, M. (2007). El pacto ambiguo. De la novela autobiográfica a la autoficción. Madrid: Biblioteca Nueva.

Bruss, E. (1991). Actos literarios. En Á. Loureiro(Ed.), La autobiografía y sus problemas teóricos. Estudios e investigación documental. Barcelona: Anthropos, 62-79.

Chirbes, R. (2014). Prólogo. En M. Sanz, La lección de anatomia (7-15). Barcelona: Anagrama.

De Man, P. (1991). La autobiografía como desfiguración.En Á. Loureiro(Ed.), La autobiografíay susproblemasteóricos. Estudios e investigación documental (113-118). Barcelona: Anthropos.

Gusdorf, G. (1991). Condiciones y límites de la autobiografía. En Á. Loureiro (Ed.), La autobiografía y sus problemas teóricos. Estudios e investigación documental (9-18). Barcelona: Anthropos.

Lejeune, P. (1991). El pacto autobiográfico. En Á. Loureiro (Ed.), La autobiografía y sus problemas teóricos. Estudios e investigación documental (47-61). Barcelona: Anthropos.

Loureiro, Á. (2000). The ethics of autobiography. Replacing the Subject in Modern Spain. Nashville: Vanderbilt University.

Niebla, R. (2015). Entrevista a Marta Sanz: "Escribir desde mi clase y desde mi género es una urgencia". Ctxt, 28 de octubre, 36, http://ctxt.es/es/20151028/Culturas/2753/Marta-Sanz-poesia-ensayo-Aranguren-Tierno-Gal van.htm.

Pozuelo Yvancos, J. M. (2006). De la autobiografía. Teoría y estilos. Barcelona: Crítica.

Sanz, M. (2010). Perra mentirosa / Hardcore. Madrid: Bartleby.

Sanz, M. (2013). Vintage. Madrid: Bartleby Editores.

Sanz, M. (2014a). No tan incendiario. Cáceres, Periférica.

Sanz, M. (2014b). La lección de anatomía. Barcelona: Anagrama.

Sanz, M. (2015). Cíngulo y estrella. Madrid: Bartleby Editores.

Scarano, L. (2014). Vidas en verso: autoficciones poéticas (estudio y antologia). Santa Fe: Universidad Nacional del Litoral.

Smith, S. (1991). Hacia una poética de la autobiografía de mujeres. En Á. Loureiro (Ed.), La autobiografía y sus problemas teóricos. Estudios e investigación documental (93-106). Barcelona: Anthropos.

\section{Notas}

1 "Pero, ¿̇tienen sentido todas estas preguntas o nos nada más que frases bonitas que derivan de una especie de filosofía de calendario? Pensemos por qué la metáfora un cuerpo es un texto podría no ser tan descabellada... Es decir, pensémoslo en clave materialista" (Sanz, 2014a, p. 98). 